\title{
Rogalsky Effect pada Bursa Efek Indonesia Tahun 2013-2017 (Studi Kasus Indeks Saham Bisnis-27)
}

\author{
Muhammad Yusril Laksana Amrullah ${ }^{1}$, Khairunnisa ${ }^{2}$ \\ Manajemen Bisnis Telekomunikasi dan Informatika, Fak.Ekonomi \& Bisnis \\ Universitas Telkom \\ yusrillaksana@ telkomuniversity.ac.id ${ }^{1}$, khairunnisa@telkomuniversity.ac.id ${ }^{2}$
}

\begin{abstract}
Market anomalies described the price of shares outstanding in the market show that performance in contravention of the concept of the capital market efficient in other words the stock price does not reflect all the information is in the capital market efficient. The purpose of this research is to see if is going on the phenomenon of market anomalies seasonal in nature namely rogalsky effect in the index bisnis-27 indonesia stock exchange a period of 2013 - 2017. A method of testing using Kolmogrov-Smirnov test to see normally distributed data, Independent Sample T-Test to hypothesis. The research data the stock price is secondary. Testing of statictic using SPSS 25 version software.

The result of this research suggests that not happened Rogalsly Effect on stock index bisnis-27 period 2013 - 2017. The implications of this research indicates that appear new phenomenon but rogalsky effect that occurs on Wednesday.The results that not found Rogalsky Effect, investors can buy stock prices than on Wednesday for a cheap price and sell back in the Wednesday with higher prices especially for January to get maximum return.
\end{abstract}

Keywords: Rogalsky Effect, Market Anomalies, Bisnis-27 Index

\begin{abstract}
Abstrak
Anomali pasar menggambarkan harga saham yang beredar didalam pasar menunjukan performa yang bertolak belakang dengan konsep pasar modal efisien dengan kata lain harga saham tidak mencerminkan seluruh informasi yang ada pada pasar modal efisien. Tujuan penelitian ini adalah untuk melihat apak ah terjadi fenomena anomali pasar bersifat musiman yaitu Rogalsky Effect pada indeks Bisnis-27 Bursa Efek Indonesia kurun waktu 2013 - 2017. Metode pengujian dilakukan dengan cara Uji KolmogrovSmirnov untuk melihat data terdistribusi secara normal, selanjutnya Uji Independent Sample T-Test untuk menguji hipotesis penelitian. Data penelitian harga saham bersifat sekunder. Pengujian statistik menggunakan software SPPS versi 25.

Hasil penelitian ini menunjukan bahwa tidak terjadi Rogalsky Effect pada Indeks saham Bisnis-27 kurun waktu 2013 - 2017. Implikasi penelitian ini mengindikasikan bahwa muncul fenomena baru selain Rogalsky Effect yang terjadi pada hari Rabu. Dengan tidak ditemukannya Rogalsky Effect ini investor dapat membeli harga saham selain hari Rabu dengan harga yang murah dan menjual kembali pada hari Rabu dengan harga yang lebih mahal khususnya bulan Januari agar mendapatkan return yang maksimal.
\end{abstract}

Kata kunci: Rogalsky Effect, Anomali Pasar, Indeks Bisnis-27

Alamat korespondensi :

JL. Telekomunikasi, Terusan Buah Batu

Fakultas Ekonomi dan Bisnis, Telkom University

Bandung, Jawa Barat 


\begin{tabular}{lll}
\hline Permalink/DOI & $:$ & http://dx.doi.org/10.32503/jmk.v4i2.488 \\
Cara Mengutip & $:$ & Amrullah, M.Y.L \& Khairunnisa. (2019). Rogalsky Effect pada \\
& Bursa Efek Indonesia Tahun 2013 - 2017 (Studi Kasus Indeks \\
& Saham Bisnis-27). JMK (Jurnal Manajemen dan \\
& Kewirausahaan), 4 (2), 146- 152 \\
& doi: http://dx.doi.org/10.32503/jmk.v4i2.488 \\
Sejarah Artikel $\quad:$ & Artikel diterima 10 April 2019; direvisi 15 April 2019; disetujui \\
& 23 April 2019
\end{tabular}

\section{Pendahuluan}

Market Anomalies di pasar modal menggambarkan saham yang tercatat menunjukan performa yang bertolak belakang dengan teori pasar modal efisien atau dengan kata lain harga saham tidak mencerminkan seluruh informasi yang ada pada pasar modal efisien. Market Anomalies merupakan Kondisi pasar modal yang bertolak belakang dengan teori pasar efisien (Jones, 2014). Konsep pasar modal yang mulai berkembang sekarang adalah konsep pasar modal efisien. Pasar modal dikatakan efisien apabila investor tidak akan memperoleh abnormal return setelah disesuaikan dengan tingkat risiko dan informasi yang beredar dalam pasar modal (Maliasari,2013). Salah satu jenis anomali pasar yaitu Rogalsky Effect, merupakan gabungan anomali pasar The Days of The Week dan January Effect yang menggambarkan harga saham cenderung naik pada hari Senin bulan Januari khususnya dibandingkan dengan hari Senin bulan lainnya. Rogalsky Effect timbul akibat tindakan rasional / irrasional seorang investor yang mempengaruhi pembentukan harga saham tersebut. Investor banyak melakukan aksi beli setelah menjual saham mereka pada bulan Desember dengan asumsi untuk mengurangi pajak (tax-loss selling), mengambil keuntungan capital gain, dan pengaruh portofolio windows dressing. Penelitian ini memilih indeks saham Bisnis-27 sebagai perhitungan tingkat return mengingat berdasarkan data histori dari tahun 2013-2017 menunjukan tren positif khususnya pada pertengahan tahun 2015 indeks bisnis-27 menunjukan tren yang stabil dibandingkan dengan indeks saham lain yang menunjukan tren negatif, dalam artian tingkat likuiditas dan return harian indeks Bisnis-27 cukup besar apabila dibandingkan dengan indeks saham lainnya seperti Jakarta Islamic Indeks, Kompas 100, dan LQ-45, dengan gambar grafik sebagai berikut :

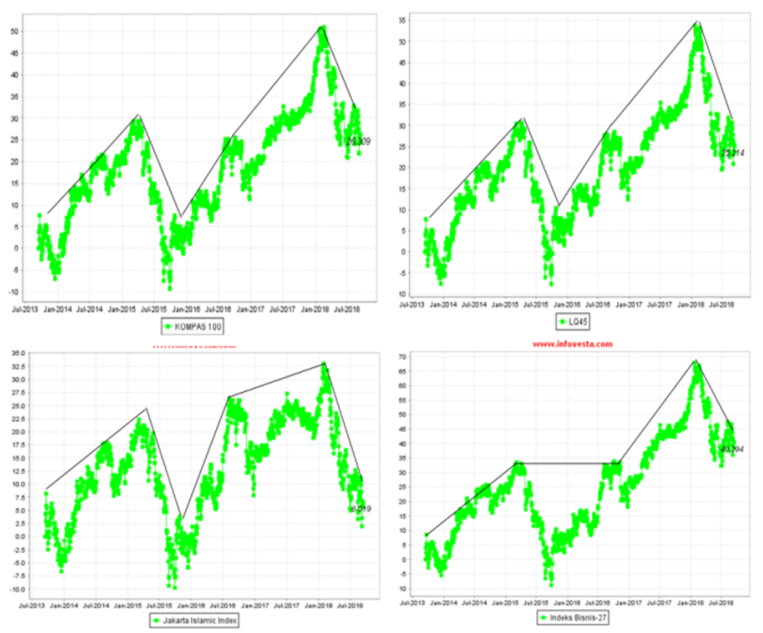

Gambar 1. Perbandingan Pergerakan Harga Indeks Saham

Penelitian ini diharapkan dapat membantu khususnya investor dalam menentukan strategi investasinya dan stakeholder pasar modal secara umum agar menambah wawasan ilmu pengetahuan tentang anomali pasar bahwasanya fenomena anomali pasar bukan untuk ditakuti 
melainkan dapat dijadikan sebagai tolak ukur dalam penentuan strategi investasi dalam pasar modal dan mengetahui financial behaviour investor di pasar modal Indonesia dalam melakukan transaksi, khususnya terkait dengan adanya anomali pasar.

\section{Tinjauan Pustaka}

\section{Investasi}

Investasi adalah komitmen atas sejumlah dana atau sumber daya lainnya yang dilakukan pada saat ini, dengan tujuan memperoleh keuntungan di masa datang (Bodie,2013).

\section{Pasar Modal}

Pasar modal adalah pertemuan antara pihak yang memiliki kelebihan dana dengan pihak yang membutuhkan dana dengan cara memperjual-belikansekuritas (Tandelilin,2017).

\section{Efficient Market Hypothesis}

Efficient Market Hypothesis

adalah Harga saham menunjukan seluruh informasi yang beredar dalam pasar. Suatu pasar modal dikatakan efisien apabila harga saham mencerminkan seluruh informasi yang beredar dalam pasar (Bodie,2013).

\section{Anomali dalam Pasar Efisien}

Anomali pasar dapat ditemukan pada semua bentuk pasar efisien. Adanya informasi asimetris yang beredar dalam pasar kerap dihubungkan dengan adanya anomali pasar. Anomali pasar merupakan kondisi pasar modal yang bertolak belakang dengan teori pasar efisien. Di dalam pasar modal anomali pasar menggambarkan adanya informasi asimetris yang dapat dilihat pada harga saham yang tidak mencerminkan seluruh informasi yang beredar (Jones, 2014)[4]. Dalam teori pasar keuangan anomali pasar dibagi menjadi emapt jenis, yaitu : Firm Anomalies, Seasonal Anomalies, Event Anomalies, dan Accounting Anomalies.

\section{Rogalsky Effect}

Rogalsky Effect adalah salah satu jenis dari anomali musiman yang menggambarkan harga saham dalam hari Senin bulan Januari cenderung naik dibandingkan dengan hari Senin bulan lainnya dalam tahun yang sama. Rogalsky Effect merupakan fenomena menghilangnya Monday Effect berkaitan dengan adanya system pelaporan keuangan. Hal tersebut mengindikasikan bahwa fenomena Monday Effect akan menghilang pada bulan Januari (Jones, 2014)[4].

\section{Return Saham}

Bahwa return saham adalah keuntungan yang diperoleh oleh perusahaan, individu dan institusi dari hasil kebijakan investasi yang dilakukan. Berdasarkan waktu pembagian return dibagi menjadi dua, yaitu return ekspektasi dan return realisasi. Return ekspektasi belum terjadi sekarang dan diharapkan dimasa mendatang. Return realisasi terjadi sekarang dan dapat digunakan sebagai dasar penentuan return ekspektasi dan risiko dimasa datang dengan menggunakan data historis. Tingkat return saham dapat dihitung dengan rumus seperti ini (Jogiyanto,2013)[3]. :

$$
R t=\frac{P t-P t^{-1}}{P t^{-1}}
$$

Rt : Return indeks saham pada hari ke $t$ 
Pt : Harga saham harian ke $\mathrm{t}$

Pt-1 : Harga saham harian pada hari ke $\mathrm{t}-1$

\section{Kerangka Pemikiran Dan Hipotesis}

Berdasarkan uraian diatas, maka kerangka pemikiran penelitian sebagai berikut:

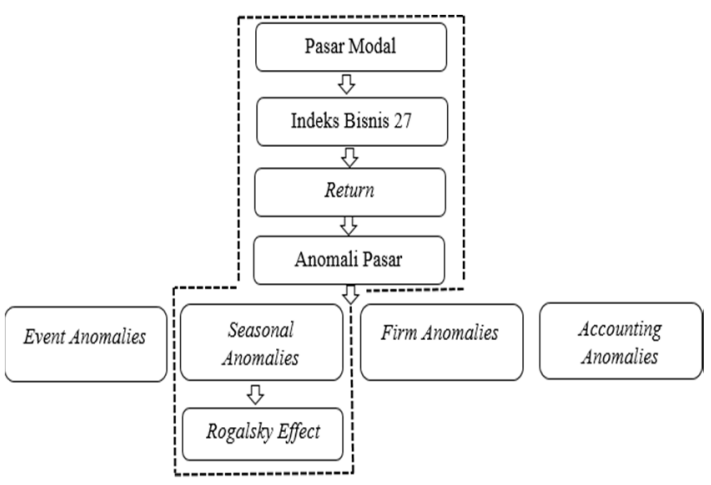

\section{Gambar 2. Kerangka Pemikiran}

\section{Hipotesis Penelitian}

Terdapat perbedaan rata-rata return saham hari Senin bulan Januari yaitu lebih tinggi dibandingkan hari Senin bulan-bulan lainnya pada tahun yang sama pada Bursa Efek Indonesia indeks saham Bisnis-27 (terjadi Rogalsky Effect) periode 2013-2017.

\section{Metodologi Penelitian}

\section{Jenis Penelitian}

Penelitian ini termasuk dalam jenis penelitian deskriptif-verifikatif dengan metode kuantitatif. Jenis data yang digunakan bersifat sekunder dengan mengambil data historis pergerakan harga saham pada lembaga keuangan.

\section{Varibel Penelitian}

Variabel yang digunakan dalam penelitian ini adalah return harian saham yang ada pada emiten indeks Bisnis-27.

\section{Populasi dan Sampel Penelitian}

Populasi dalam penelitian ini adalah emiten yang secara konsisten terdaftar dalam Indeks saham Bisnis27 tahun 2013-2017. Metode pengambilan sampel yang digunakan dalam penelitian ini adalah pengambilan sampel non probabilitas dengan teknik purposive sampling. Adapun kriteria sampel yang digunakan dalam penelitian ini adalah sebagai berikut:

1. Emiten yang terdaftar secara konsisten dalam Indeks Bisnis-27 selama periode 2013 - 2017

2.Emiten yang tidak melakukan corporate action

\section{Uji Normalitas}

Tujuan utama uji normalitas adalah melihat apakah data terdistribusi secara normal atau tidak. Langkah ini dilakukan sebelum pengujian hipotesis. Pengujian normalitas dilakukan dengan cara Uji One Sample Kolmogrov-Smirnov. Hasil uji One Sample KolmogrovSmirnov dapat dilihat pada tabel, normalitas data dapat dilihat dari besarnya signifikansi. Jika nilai signifikansi >0,05, maka data terdistribusi secara normal dan begitu pula sebaliknya

\section{Uji Independent Sample T-Test}

Hasil uji normalitas menunjukan data terdistribusi secara normal, maka pengujian hipotesis dilakukan dengan teknik Uji Independent Sample T-test yang berguna untuk melakukan pengujian terhadap sampel yang berasal dari populasi. Uji Independent Sample Ttest ini dilakukan untuk menguji apakah ada perbedaan rata-rata return saham pada hari Senin bulan Januari dibandingkan dengan hari Senin bulan lainnya pada tahun yang sama. 
Pengambilan hasil keputusan berdasarkan probabilitas

H0 : rata-rata return hari Senin bulan Januari $\leq$ rata- rata return hari Senin bulan lainnya ( Tidak terjadi Rogalsky Effect )

H1 : rata-rata return hari Senin bulan Januari > rata-rata return hari Senin bulan lainnya ( Rogalsky Effect )

Jika nilai signifikansi Sig.(2-tailed) $\leq 0,05$, maka H0 ditolak

Jika nilai signifikansi Sig.(2-tailed)

$>0,05$, maka H0 diterima.

\section{Hasil}

\section{Uji Normalitas}

Uji normalitas data bertujuan untuk mengetahui apakah data terdistribusi secara normal dan untuk menentukan metode pengujian selanjutnya. Uji normalitas yang digunakan dalam penelitian ini adalah One-Sample Kolmogorov- Smirnov Test. Jika nilai asymptonic Sig. (2tailed) > 0,05 maka data terdistribusi secara normal. Sebaliknya jika nilai asymptonic Sig. (2-tailed) $<0,05$ maka data tidak terdistribusi secara normal. Hasil pengujian uji normalitas pada penelitian ini tersaji dalam tabel berikut :

\section{Tabel 1. Hasil uji normalitas} one sample kolmogorov-smirnov

\begin{tabular}{|ll|c|}
\hline & & Return \\
\hline $\mathrm{N}$ & & 60 \\
\hline Normal Parameters & Mean & 0.000449 \\
\hline & Std. Deviation & 0.0076292 \\
\hline Most Extreme Differences & Absolute & 0,049 \\
\hline & Positive & 0,049 \\
\hline & Negative & $-0,049$ \\
\hline Test Statistic & & 0,049 \\
\hline Asymp. Sig. (2-tailed) & & $0,075^{\circ}$ \\
\hline
\end{tabular}

Sumber: Data diolah (2019)
Dari hasil pengujian uji normalitas menggunakan metode One-Sample Kolmogorov- Smirnov Test diatas diketahui nilai asymptonic Sig. (2-tailed) sebesar 0,075 lebih besar dari 0,05 (0,075 > $0,05)$, artinya data terdistribusi secara normal. Untuk pengujian selanjutnya menggunakan metode Independent Sample T-Test.

\section{Pengujian Hipotesis}

Hipotesis pada penelitian ini adalah terdapat perbedaan rata-rata return saham hari Senin bulan Januari lebih tinggi dibandingkan hari Senin bulan-bulan lainnya pada tahun yang sama pada Bursa Efek Indonesia indeks saham Bisnis-27 (terjadi Rogalsky Effect) periode 2013-2017. Pengujian hipotesis menggunakan metode Independent Sample T-Test karena data terdistribusi secara normal, dengan hasil pengujian sebagai berikut :

Tabel 2 Hasil uji independent sample t-test rogalsky effect 20132017

\begin{tabular}{|c|c|c|}
\hline & Januari & Non Januari \\
\hline Senin & $\begin{array}{c}-0.0063 \\
(0.868)\end{array}$ & -0.0043 \\
\hline Selasa & $\begin{array}{l}0.0031 \\
(0.377)\end{array}$ & 0.0003 \\
\hline Rabu & $\begin{array}{c}0.0057 \\
(0.426)\end{array}$ & 0.0029 \\
\hline Kamis & $\begin{array}{c}-0.0001 \\
(0.755)\end{array}$ & 0.0009 \\
\hline Jumat & $\begin{array}{c}0.0029 \\
(0.179)\end{array}$ & -0.0011 \\
\hline
\end{tabular}

Sumber: Data diolah (2019)

Berdasarkan tabel 2 diatas pada tahun 2013 - 2017 nilai sig. ( 2tailed ) hari Senin bulan Januari sebesar 0.868 lebih besar dari 0,05 (0.868 > 0.05), maka H0 diterima, artinya bahwa tidak terjadi Rogalsky Effect pada tahun 2013 - 2017. Ratarata return hari Senin bulan Januari 0.0063 berbeda dari rata-rata return 
bulan Non-Januari sebesar -0.0043 ($0.0063<-0.0043)$, artinya terdapat perbedaan rata-rata return hari Senin bulan Januari dan Non-Januari. Secara keseluruhan, rata- rata return hari Selasa bulan Januari 0.0031 berbeda dari rata-rata return bulan Non-Januari sebesar 0.0003 (0.0031 > $0.0003)$, artinya terdapat perbedaan rata-rata return hari Selasa bulan Januari dan Non-Januari secara signifikan. Rata-rata return hari Rabu bulan Januari 0.0057 berbeda dari rata- rata return bulan Non-Januari sebesar $0.0029(0.0057>0.0029)$, artinya terdapat perbedaan rata- rata return hari Rabu bulan Januari dan Non- Januari secara signifikan. Ratarata return hari Kamis bulan Januari 0.0001 berbeda dari rata-rata return bulan Non-Januari sebesar 0.0009 ($0.0001<0.0009)$, artinya terdapat perbedaan rata-rata return hari Kamis bulan Januari dan Non-Januari secara signifikan. Rata-rata return hari Jumat bulan Januari 0.0029 berbeda dari rata-rata return bulan Non-Januari sebesar -0.0011 (0.0029> -0.0011), artinya terdapat perbedaan rata-rata return hari Jumat bulan Januari dan Non-Januari secara signifikan. Secara keseluruhan pada tahun 2013 - 2017 terdapat perbedaan rata-rata return setiap hari antara bulan Januari dan Non-Januari dengan nilai rata-rata return tertinggi terjadi pada hari Rabu bulan Januari dengan nilai sebesar 0.0057 dan terendah terjadi pada hari Senin bulan Januari sebesar -0.0063.

\section{Pembahasan}

Muncul suatu fenomena baru bahwasanya terdapat anomali baru yang bisa terjadi dihari selain Senin, yaitu pada hari Rabu dengan melihat nilai rata-rata return saham yang positif dan lebih tinggi dibandingkan dengan rata-rata return saham bulan
Januari dan Non-Januari. Dalam hal ini investor membeli saham pada hari selain Rabu dengan harga yang murah dan menjual kembali pada hari Rabu dengan tingkat return yang lebih besar dibandingkan hari lainnya. Fenomena tidak adanya Rogalsky Effect pada indeks Bisnis 27 ini terjadi salah satunya karena didukung adanya aksi investor untuk menjual saham yang tidak mempunyai prospek positif dimasa akan datang dan bergerak negatif, khususnya melakukan aksi jual pada akhir tahun dan membeli kembali di tahun selanjutnya dengan harapan memperoleh capital gain atau sering dikenal dengan istilah window dressing. Ketika investor menjual saham yang tidak mempuyai prospek positif di akhir tahun tersebut, maka harga saham yang bersangkutan akan turun pada bulan Januari dan mempengaruhi tingkat return.

Hasil penelitian ini adalah tidak terjadi fenomena Rogalsky Effect pada indeks Bisnis-27 berdasarkan hasil hitung probabilitas dan adanya perbedaan rata-rata return signifikan hari Senin bulan Januari dan Senin bulan Non-Januari. Dengan tidak ditemukan Rogalsky Effect bahwasanya terjadi penurunan tingkat rata-rata return atau return hari Senin bulan Januari lebih kecil daripada Senin bulan non Januari. Hal tersebut dapat dipengaruhi oleh financial behaviour seorang investor yang lebih memilih memegang uang secara langsung daripada berspekulasi pada saham. Investor menunggu reaksi emiten pada tahun selanjutnya terhadap strategi dan aksi emiten. Selain itu investor cenderung tidak mengikuti perkembangan pasar akibat banyaknya hari libur di akhir tahun dan awal tahun. Kekurangan informasi inilah yang mempengaruhi 
investor untuk cenderung memegang uang secara kas.

\section{Simpulan}

Penelitian ini bertujuan untuk mengidentifikasi ada atau tidak anomali pasar musiman yaitu Rogalsky Effect pada indeks saham Bisnis-27 kurun waktu 2013 - 2017. Penelitian ini mencakup sembilan emiten yang terdaftar secara konsisten dan tidak melakukan corporate action selama periode 2013 - 2017 dalam indeks saham Bisnis-27. Berdasarkan hasil pengujian dan analisis yang telah dilakukan maka kesimpulan dari hasil penelitian ini yaitu :

1. Tidak terjadi fenomena anomali musiman Rogalsky Effect pada tahun 2013 - 2017 pada indeks saham Bisnis-27. Nilai rata-rata return hari Senin bulan Januari sebesar -0.0063 berbeda dengan rata-rata return bulan Non Januari sebesar - 0.0043 .

2. Implikasi dari hasil penelitian ini adalah muncul suatu fenomena baru selain Rogalsky Effect. Hal tersebut dapat dilihat pada hasil rata-rata return hari Rabu lebih besar dari hari lainnya dan terdapat perbedaan rata-rata return hari Rabu bulan Januari dan Rabu bulan Non Januari.

\section{Daftar Pustaka}

Bodie, Z., Kane, A., \& Marcus, A. J. (2013). Essentials of Investment, Ninth Edition. New York: McGraw-Hill/Irwin Companies.

Fahmi, I. (2015). Pengantar Teori Portofolio dan Analisis Investasi. Bandung: Alfabeta.
Jogiyanto, H. (2013). Teori Portofolio dan Analisis Investasi. Edisi. Yogyakarta: BPFE.

Jones, C. P. (2014). Investments Analysis and Management. Twelfth Edition. Singapore: John Wiley and Sons Singapore Pte Ltd.

Maliasari, K. (2013). Pengaruh January Effect dan Rogalsky Effect Terhadap Abnormal Return Saham dan Trading Volume Activity. Jurnal Ilmiah Mahasiswa FEB Univeristas Brawijaya, 02.

Satoto, S. H. (2011). Analisis Fenomena Day of The Week Effect : Pengujian Monday Effect, Week-Four Effect, dan Rogalski Effect (Studi Empiris pada Perusahaan LQ 45 di BEI). Jurnal Manejemen Vol.10 No.2.

Tandelilin, E. (2017). Portofolio dan Investasi Teori dan Aplikasi. In E. Tandelilin, Portofolio dan Investasi Teori dan Aplikasi ( $p$. 2). Yogyakarta: Kanisius. 